\title{
Aislamiento de Listeria monocytogenes en productos lácteos, artesanales y hortalizas
}

\author{
Edgardo Tzoc Ramírez* \\ Silvia Pineda*
}

\section{RESUMEN}

Listeria monocytogenes, una bacteria común del suelo. Es conocida desde hace tiempo por su importancia veterinaria causando pérdidas económicas considerables. En la actualidad, es un reconocido patógeno para el ser humano que afecta principalmente neonatos, mujeres embarazadas y personas inmunodeprimidas. Su transmisión es generalmente por alimentos contaminados, entre los principales vehículos están los lácteos y los vegetales que se consumen crudos. El objetivo de este estudio fue evaluar la calidad microbiológica de productos lácteos producidos artesanalmente y de hortalizas listas para consumo, a través del análisis de L. monocytogenes. La metodología empleada para este propósito es la indicada en el Bacteriological Analytical Manual (BAM) de la Food and Drug Administration (FDA) de Estados Unidos. Ésta consiste en el uso de medios para enriquecimiento y altamente selectivos para el aislamiento de la bacteria. Resultados: se analizaron un total de 80 muestras de productos lácteos (mantequilla crema y rala, queso seco y fresco, quesillo y requesón) además se analizaron 20 muestras de hortalizas (lechuga, repollo, brócoli, espinaca y coliflor). Solamente se obtuvo un aislamiento a partir de una muestra de requesón, lo cual representa apenas un 1 por ciento de positividad. Conclusiones: Listeria es una bacteria que se encuentra contaminando los alimentos, especialmente los que no sufren ningún proceso de preparación previo a su consumo. A pesar del bajo porcentaje de aislamiento obtenido no se debe descartar el potencial riesgo de este tipo de alimentos para el consumidor final en particular los grupos de mayor riesgo.

\section{Palabras clave:Listeria, lácteos, hortalizas, Honduras}

\footnotetext{
* Edgardo Tzoc, Msc. en Microbiología. Facultad de Ciencias, Escuela de Microbiología, UNAH. Sección de bacteriología, etzoc2000@yahoo.com.

* Silvia Pineda, Microbióloga y Químico Clínico. Facultad de Ciencias, Escuela de Microbiología, UNAH. Sección de bacteriología.
} 


\section{ABSTRACT}

Listeria monocytogenes a common soil bacterium, is long known for its veterinary importance causing major economic losses. Today is a recognized pathogen for humans that primarily affect newborn infants, pregnant women and immunosuppressed people. Its transmission is usually through contaminated food like dairy products and vegetables consumed raw, are the main vehicles. The aim of this study was to evaluate the microbiological quality of dairy products produced by hand and vegetables ready for use through the analysis of $L$. monocytogenes. The methodology used for this purpose is specified in the Bacteriological Analytical Manual (BAM) of the Food and Drug Administration (FDA) of the United States. This involves the use of medias to get a highly and selective enrichment and isolation of the bacteria. Results: A total of 80 samples of milk products (butter cream and thin, dry and fresh cheese, cheese and cottage cheese) also analyzed 20 samples of vegetables (lettuce, cabbage, broccoli, spinach and cauliflower) where analyzed. Only one isolate was obtained from a sample of cheese, which represents only $1 \%$ positivity. Conclusions: Listeria is a bacterium that is contaminating the food, especially those who do not undergo any process of preparation prior to consumption. Despite the low percentage of isolation obtained should not be dismiss the potential risk of this type of food to final the consumers in particular those that are at greatest risk.

Key words: Listeria, dairy, fresh produce, Honduras 


\section{INTRODUCCIÓN}

La asociación entre Listeria monocytogenes y la generación de enfermedad en el ser humano es un hecho conocido desde hace ya bastante tiempo. Más aún, la transmisión oral de esta bacteria a través de diferentes alimentos también ha sido evaluada en multitud de estudios realizados en todo el mundo ${ }^{1,2,3,4,5,6}$.

Esta bacteria es una de las patógenas más importantes de origen alimentario, dado que resiste diversas condiciones ambientales como $\mathrm{pH}$ bajo, altas concentraciones de sal y, sobre todo, tiene la capacidad de sobrevivir a temperaturas de refrigeración $\left(2-4^{\circ} \mathrm{C}\right)$ y tratamientos inadecuados de pasteurización, logrando que se constituya en una seria amenaza de salud pública y un grave problema para la industria alimentaria ${ }^{2,4}$. Los alimentos más comúnmente implicados son los productos lácteos, cárnicos y vegetales, en general productos que se refrigeran y se consumen sin cocinar o calentar. Por estas razones se piensa que el tracto gastrointestinal es la principal puerta de entrada ${ }^{7,8,9}$.

Entre los años 80 y 90, la presencia de la Listeria monocytogenes se comenzó a considerar como un problema de salud pública en Estados Unidos, Canadá y algunos países de Europa donde se presentaron brotes importantes de listeriosis reportándose como una de las enfermedades emergentes transmitidas por

${ }^{1}$ Arias - Echandi ML y Antillon F. 2000. Contaminación microbiológica de los alimentos en Costa Rica, Una revisión de 10 años. Rev Biomed 11:113-122.

${ }^{2}$ Borges M, Siqueira R, Bittencourt A, Vanetti M y Gomide L. 1999. Ocurrence of Listeria monocytogenes in salami. Revista de Microbiología 30: 362-364.

${ }^{3}$ De Curtis ML, Franceschi O, y De Castro N. 2002. Listeria monocytogenes en vegetales mínimamente procesados. Archivos latinoamericanos de nutrición Vol. 52 (3).

${ }^{4}$ Espinoza A, De La Torre M, Salinas M, Sánchez V. 2004. Determinación de Listeria monocytogenes en quesos frescos de producción artesanal que se expenden en los mercados del distrito de Ica, enero - marzo 2003. Rev. Perú. med. exp. Salud Pública v.21 n.2 Lima abr./jun. 2004.

${ }^{5}$ García H, Pinto E, Ross y Saavedra G. 1980. Brote epidémico de listeriosis neonatal. Revista Chilena de Pediatría. Vol.54 (5).

${ }^{6}$ Martínez R y Villalobos de Bastardo L. 2004. Aislamiento de Listeria monocytogenes en atún fresco expedido en la ciudad de Cumaná, Venezuela. Revista Científica Vol. 14 (4).

${ }^{7}$ Martino Zagovalov T, Leyva Castillo V, Pérez Chang A, de los Reyes M, Suárez Herrera y Lara Ortiz C. 2005. Determinación de Listeria spp. en quesos y embutidos comercializados en Cuba. Rev Cubana Salud Pública Vol. 31 (3).

${ }^{8}$ Marzocca MA, Marucci PL, Sica MG y Álvarez E. 2004. Detección de Listeria monocytogenes en distintos productos alimenticios y en muestras ambientales de una amplia cadena de supermercados de la ciudad de Bahía Blanca, Argentina. RevistaArgentina de Microbiología, 36: 179-181.

${ }^{9}$ Vásquez-Boland J, Kuhn M, Berche P, Chakraborty T, Bernal G, Goebel W, Gonzales B, Wehland J y Kreft J. 2001. Listeria pathogenesis and molecular virulence determinants. Clinical Microbiology Reviews 14 (3): 584-640. 
alimentos (ETA's) más importantes ${ }^{3}$. La listeriosis es una enfermedad que se presenta principalmente en individuos inmunocomprometidos debido a diversas causas: alcoholismo, HIV, adicción a drogas, terapias prolongadas, los extremos de edad y el embarazo ${ }^{2,3,7}$.

Puede presentarse esporádicamente o en epidemias; en ambas situaciones, los alimentos contaminados son los principales vehículos de transmisión de $L$. monocytogenes. La leche, el queso, los vegetales frescos, la berza, el pollo, las setas, el pavo y muchos otros suelen ser los alimentos más frecuentemente implicados en ella. La incidencia anual por 100,000 habitantes puede variar del 0.3 al $0.8 \%$ y alcanzar un 5 por ciento durante algunos brotes epidémicos.

A nivel latinoamericano también se han reportado problemas de salud ocasionados por esta bacteria. En diversos países se han presentado como brotes de listeriosis neonatal aislándose de la sangre y del líquido cefalorraquídeo de los pacientes ${ }^{5}$.

Ante esta panorámica desde hace algún tiempo las agencias reguladoras de diferentes países han adoptado normativas en relación con Listeria monocytogenes en productos específicos listos para comer por el riesgo que supone para la salud humana y por el problema económico que representa para el comercio internacional. La presencia de cualquier especie de Listeria en un alimento procesado es indicativo de que su eliminación no fue llevada a cabo de forma efectiva durante el procesamiento del alimento.

En Europa, según la directriz 92/46/EC, L. monocytogenes no debe estar presente en $25 \mathrm{gr}$ de queso blando y los hallazgos positivos llevan a un reprocesamiento del producto. Así mismo, en Estados Unidos y Canadá tienen establecido dentro de su legislación la "Cero tolerancia" para este patógeno, en alimentos como leche y productos cárnicos ${ }^{10}$.

\footnotetext{
${ }^{2}$ Borges M, Siqueira R, Bittencourt A, Vanetti M y Gomide L. 1999. Ocurrence of Listeria monocytogenes in salami. Revista de Microbiología 30: 362-364.

${ }^{3}$ De Curtis ML, Franceschi O, y De Castro N. 2002. Listeria monocytogenes en vegetales mínimamente procesados. Archivos latinoamericanos de nutrición Vol. 52 (3).

${ }^{5}$ García H, Pinto E, Ross y Saavedra G. 1980. Brote epidémico de listeriosis neonatal. Revista Chilena de Pediatría. Vol. 54 (5).

${ }^{7}$ Martino Zagovalov T, Leyva Castillo V, Pérez Chang A, de los Reyes M, Suárez Herrera y Lara Ortiz C. 2005. Determinación de Listeria spp. en quesos y embutidos comercializados en Cuba. Rev Cubana Salud Pública Vol. 31 (3).

${ }^{10}$ Rivera F, Wesley I, Hurd S, Simoes D, SosaAy Rivera S. 2006. Determinación Microbiológica y Molecular de Listeria sp. y Listeria monocytogenes en Cerdas a nivel de una planta beneficiadora en EUA. Revista Científica Vol. 16 (3).
} 
La evaluación de la calidad de los productos alimenticios destinados al consumo humano en nuestro país ha estado limitada al análisis de ciertas bacterias y con más énfasis en productos destinados a la exportación. Por el contrario los productos de tipo artesanal, listos para el consumo no reciben ningún tipo de control por parte del gobierno, más que estudios esporádicos, dirigidos a evaluar la contaminación de tipo microbiológico por medio de la detección y recuento de microorganismos indicadores, que en suma no revelan el riesgo potencial a la salud ya que no detectan la mayoría de bacterias involucradas en enfermedades transmitidas por alimentos (ETA).

Los productos lácteos elaborados artesanalmente y los vegetales que se consumen crudos ofrecen condiciones favorables para el crecimiento de Listeria. Los lácteos porque son elaborados a partir de leche cruda sin pasteurización, inadecuadas prácticas de manufactura, que sumados a la alta humedad y al hecho de no estar sujetos a controles de almacenamiento, distribución y expendio se convierten en un vehículo potencial de transmisión para $L$. monocytogenes y otros microorganismos patógenos ${ }^{4}$. En adición el uso de aguas residuales para riego y la defecación al aire libre contribuyen a esta contaminación.

\section{MÉTODOSYTÉCNICAS}

1. Diseño experimental: este es un estudio descriptivo, en el cual se determinó la presencia o ausencia de Listeria monocytogenes en alimentos altamente susceptibles de contaminación.

2. Muestreo: se definió un tamaño de 100 muestras analíticas. Se recolectaron 80 muestras de productos lácteos. De éstos, 60 producidos de manera artesanal, es decir productos elaborados de manera tradicional utilizando leche cruda y sin estrictos controles de calidad y 20 de productos elaborados bajo condiciones adecuadas de higiene. Además se recolectaron 20 muestras de productos hortícolas. Las muestras de lácteos artesanales y de hortalizas se recolectaron en diferentes mercados de Tegucigalpa y Comayagüela. Los productos lácteos industrializados se recolectaron en supermercados.

Entre los productos lácteos se encuentran el queso fresco y el quesillo, en parte porque son reconocidos por albergar una gran carga microbiana y además

\footnotetext{
${ }^{4}$ EspinozaA, De La Torre M, Salinas M, Sánchez V. 2004. Determinación de Listeria monocytogenes en quesos frescos de producción artesanal que se expenden en los mercados del distrito de Ica, enero - marzo 2003. Rev. Perú. med. exp. Salud Pública v.21 n.2 Lima abr./jun. 2004.
} 
porque tienen una gran demanda y consumo entre la población general. Además mantequilla crema y rala. De las hortalizas se tomaron muestras de brócoli, coliflor, espinaca, repollo y lechuga.

3. Análisis microbiológico: El aislamiento de Listeria se hizo de acuerdo a lo establecido en el Bacteriological Analitycal Manual (BAM) de la Food and Drug Administration (FDA), tal y como se describe a continuación:

a. Enriquecimiento: se tomaron 25 gr de cada muestra de producto, con ayuda de un cuchillo y una bandeja estériles. Luego se homogenizó con $225 \mathrm{ml}$ de caldo de Enriquecimiento Base Listeria Buferado (CLEB Oxoid @), de forma manual durante un minuto; posteriormente, se incubó a $30^{\circ} \mathrm{C}$ durante 24 a 48 horas.

b. Aislamiento: a partir del caldo CLEB incubado por 24 y 48 horas se sembró en agar Oxford (Oxoid $\left.{ }^{\circledR}\right)$ por estría y agotamiento, luego se incubó a $35^{\circ} \mathrm{C}$ durante 24 y 48 horas.

c. Identificación preliminar: los aislamientos sospechosos de ser Listeria cumplieron con estas características: colonias aisladas en el medio selectivo, y que presentaron las características principales: color negro por degradación de la esculina, pequeñas de borde entero y depresión central. También se realizó una coloración de Gram en la que se observan cocobacilos Gram positivos. Además las pruebas de catalasa (+), oxidasa (-) y movilidad a $30^{\circ} \mathrm{C}(+)$. Las cepas sospechosas se guardaron en leche descremada a $-70^{\circ} \mathrm{C}$ para su posterior identificación por pruebas bioquímicas.

d. Pruebas para diferenciar género y especie: se utilizó el sistema de identificación API Listeria (BioMériux ®).

\section{RESULTADOS}

El estudio reveló un porcentaje muy bajo de positividad de aislamiento de Listeria monocytogenes de apenas 1 por ciento del total de muestras recolectadas. Con respecto a los productos hortícolas no se obtuvieron aislamientos en ninguna de las muestras recolectadas. 
Tabla 1. Resultados de aislamiento de Listeria monocytogenes de muestras de productos lácteos y hortícolas recolectados en mercados y supermercados de la ciudad de Tegucigalpa. Noviembre 2008-agosto 2010.

\begin{tabular}{l|c|c|}
\hline Tipo de muestra & $\begin{array}{c}\text { No. de muestras } \\
\text { analizadas }\end{array}$ & $\begin{array}{c}\text { No. de muestras } \\
\text { analizadas (\%) }\end{array}$ \\
\hline Lácteos artesanales & 60 & $1(1.5 \%)$ \\
\hline Lácteos industriales & 20 & 0 \\
Hortalizas & 20 & 0 \\
\hline Total & 100 & $1(1 \%)$
\end{tabular}

Este porcentaje aumenta ligeramente si se toman en cuenta únicamente los productos lácteos $(1.25 \%)$ o los lácteos artesanales (1.5\%) y dentro de éstos los quesos blandos (3.33\%).

Tabla 2. Resultados de análisis microbiológico de muestras de productos lácteos artesanales recolectados en mercados de la ciudad de Tegucigalpa. Noviembre 2008-agosto 2010.

\begin{tabular}{l|c|c|c|} 
Tipo de muestra & $\begin{array}{c}\text { No. de muestras } \\
\text { analizadas }\end{array}$ & $\begin{array}{c}\text { No. de muestras } \\
\text { positivas por } \\
\text { Listeria }\end{array}$ & $\begin{array}{c}\text { \% de muestras } \\
\text { positivas por } \\
\text { Enterococcus y } \\
\text { Staphylococcus }\end{array}$ \\
\hline Quesos blandos & 30 & 1 & 100 \\
Quesos duros & 15 & 0 & 100 \\
Mantequillas & 10 & 0 & 100 \\
\hline Total & 60 & 1 & 100
\end{tabular}

Aunque el estudio estaba dirigido al aislamiento de Listeria monocytogenes, se obtuvieron resultados altos con respecto al aislamiento de otros géneros de bacterias indicadoras en los productos lácteos, especialmente los artesanales, como Enterococcus y Staphylococcus, los cuales pueden ser bastante similares a Listeria en sus características coloniales. Como se puede observar el 100 por ciento de las muestras resultó positivo para estos dos géneros. 
Tabla 3. Resultados de aislamiento de Listeria monocytogenes por tipo de productos lácteos artesanales recolectados en mercados de la ciudad de Tegucigalpa. Noviembre 2008-agosto 2010.

\begin{tabular}{l|c|c|c|c|}
\multirow{2}{*}{ Tipo de muestra } & $\begin{array}{c}\text { No. de } \\
\text { muestras } \\
\text { analizadas }\end{array}$ & \multicolumn{3}{|c}{ Muestra positivas por } \\
\cline { 3 - 5 } & 15 & 0 & 15 & 15 \\
Quesillo & 10 & 0 & 10 & 10 \\
Queso fresco & 5 & 0 & 5 & 5 \\
Queso con chile & 5 & 1 & 5 & 5 \\
Requesón & 5 & 0 & 5 & 5 \\
Queso seco & 5 & 0 & 5 & 5 \\
Queso semiseco & 5 & 0 & 5 & 5 \\
Queso ahumado & 5 & 0 & 5 & 5 \\
Mantequilla rala & 5 & 0 & 5 & 5 \\
Mantequilla crema & 5 & 1 & 60 & 60 \\
Total & 60 & 1 & & Staphylococcus \\
\hline
\end{tabular}

Como era de esperarse, en las muestras de quesos procesados industrialmente no se obtuvo aislamiento de Listeria ni de bacterias de otros géneros con significancia para la salud.

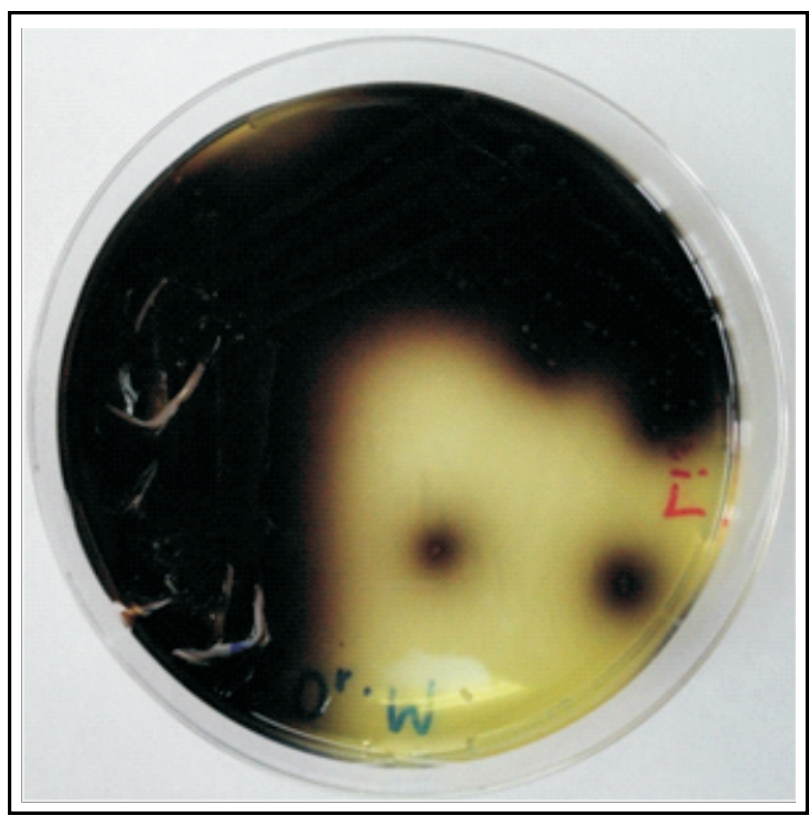

Figura 1. Aislamiento típico de Listeria monocytogenes en agar Oxford. 


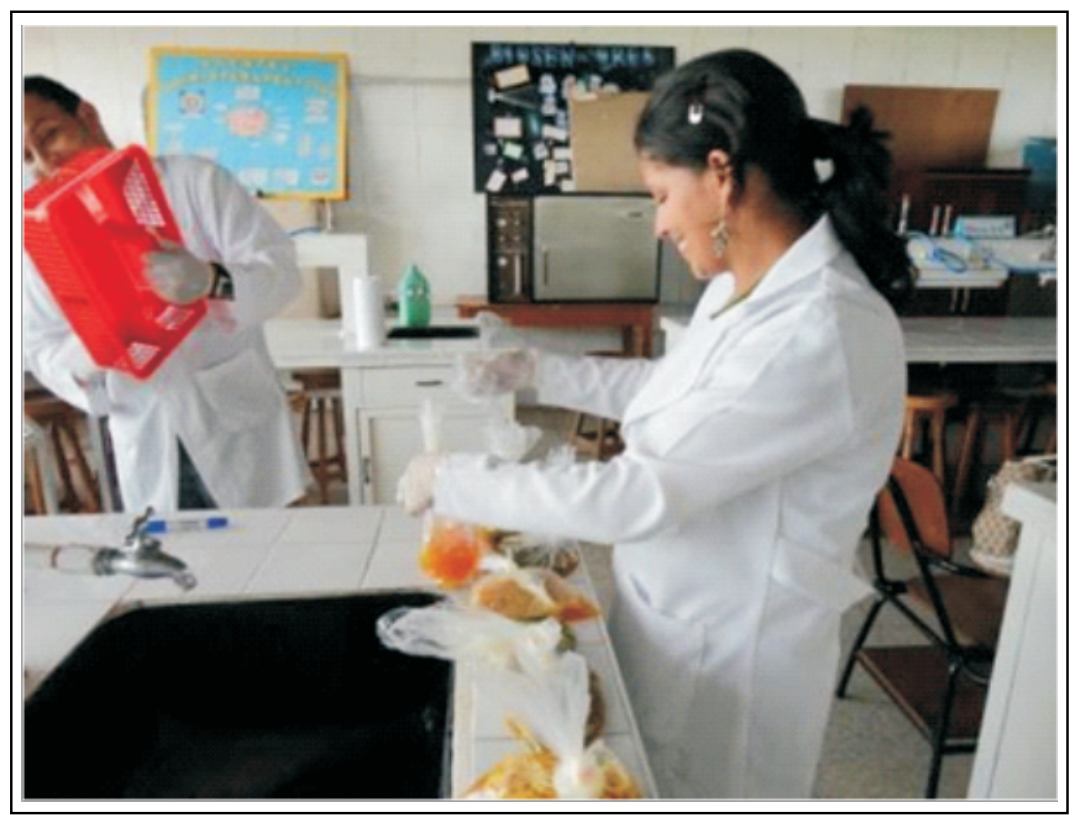

Figura 2. Alumnos de la clase de investigación procesando las muestras para análisis.

\section{DISCUSIÓN}

Los quesos blandos producidos artesanalmente son de los productos lácteos que ofrecen condiciones favorables para el crecimiento de Listeria porque son elaborados a partir de leche cruda sin pasteurización, inadecuadas prácticas de manufactura, que sumados a la alta humedad y al hecho de no estar sujetos a controles de almacenamiento, distribución y expendio, se convierten en un vehículo potencial de transmisión para L. monocytogenes y otros microorganismos patógenos ${ }^{4}$.

Aunque el estudio tiene como ámbito geográfico a la ciudad capital, ésta es representativa de lo que ocurre en otras zonas del país. Los productos que se expenden en los mercados capitalinos provienen de las principales zonas productoras de la zona sur y oriental del país (departamento de Choluteca y Olancho). Por otra parte, estos productos no son consumidos sólo por población de

\footnotetext{
${ }^{4}$ EspinozaA, De La Torre M, Salinas M, Sánchez V. 2004. Determinación de Listeria monocytogenes en quesos frescos de producción artesanal que se expenden en los mercados del distrito de Ica, enero - marzo 2003. Rev. Perú. med. exp. Salud Pública v.21 n.2 Lima abr./jun. 2004.
} 
bajos recursos, sino que por personas de todos los estratos de la sociedad hondureña porque forman parte de nuestra alimentación diaria. La presencia de $L$. monocytogenes en requesón como parte del grupo de quesos blandos resultó menor que la demostrada en la mayoría de estudios realizados en diversos países de Latinoamérica. En Cuba y Argentina se obtuvieron resultados más altos que en nuestro país en muestras de quesos blandos, pero significativamente más bajos que en Costa Rica, donde se reportan porcentajes de hasta 45 por ciento. Sin embargo, es de hacer notar que en los dos primeros países esos datos se derivan de estudios puntuales como el nuestro, en tanto que en Costa Rica, esos datos se obtuvieron por el análisis sistemático durante más de 10 años ${ }^{1,7,8}$. Por otra parte, estudios en Venezuela fallaron en obtener aislamientos de Listeria spp. en productos similares. Asimismo, en Brasil los rangos varían grandemente, desde tan bajos como 0.5 por ciento hasta tan altos como 46 por ciento ${ }^{11,12}$.

La presencia de Listeria depende de muchas variables, su presencia no es normal en los animales aunque en ellos es un patógeno más frecuente que para el ser humano, así que el manejo del ganado, las condiciones ambientales, las prácticas de manufactura, el transporte, el almacenamiento y las condiciones de venta inciden en la presencia de esta en el producto que se expende. Por esta razón no es de extrañar la alta variabilidad entre los datos obtenidos entre diferentes países, y aún en un mismo país. Con respecto al aislamiento de otras bacterias que son indicadoras de la calidad microbiológica como los Enterococcus y los Staphylococcus, los resultados de 100 por ciento de contaminación. Adiferencia de los obtenidos para Listeria, este resultado es congruente con los obtenidos en otros países y en estudios previos en nuestro mismo pais ${ }^{4,11,13}$. Probablemente, debido a

\footnotetext{
${ }^{1}$ Arias - Echandi ML y Antillon F. 2000. Contaminación microbiológica de los alimentos en Costa Rica, Una revisión de 10 años. Rev Biomed 11:113-122.

${ }^{4}$ Espinoza A, De La Torre M, Salinas M, Sánchez V. 2004. Determinación de Listeria monocytogenes en quesos frescos de producción artesanal que se expenden en los mercados del distrito de Ica, enero - marzo 2003. Rev. Perú. med. exp. Salud Pública v.21 n.2 Lima abr./jun. 2004.

${ }^{7}$ Martino Zagovalov T, Leyva Castillo V, Pérez Chang A, de los Reyes M, Suárez Herrera y Lara Ortiz C. 2005. Determinación de Listeria spp. en quesos y embutidos comercializados en Cuba. Rev Cubana Salud Pública Vol. 31 (3).

${ }^{8}$ Marzocca MA, Marucci PL, Sica MG y Álvarez E. 2004. Detección de Listeria monocytogenes en distintos productos alimenticios y en muestras ambientales de una amplia cadena de supermercados de la ciudad de Bahía Blanca, Argentina. RevistaArgentina de Microbiología, 36: 179-181.

${ }^{11}$ Márquez J. y García C. 2007. Microflora patógena del queso blanco telita elaborado en cuatro estados de Venezuela. An Venez Nutr 20 (1):17-21.

${ }^{12}$ Moscalewski W, Da Silva P, Leise C, Pontarolo R. 2008. Ocurrence of Listeria monocytogenes in cheese and ice cream produced in the State of Parana, Brazil. Braz J Pharm Sciences 44 (2): 289-296.

${ }^{13}$ Padilla G, Tzoc E y Sabillón L. 1995. Investigación de la contaminación microbiológica de productos lácteos producidos en forma artesanal. Monografía CESCCO.
} 
que estos dos géneros de bacterias son frecuentes comensales del ganado vacuno, no es de extrañar que se encuentren en grandes cantidades en la leche, y si ésta no es pasteurizada previo a su uso en la producción de quesos, su número aumenta a niveles realmente alarmantes.

Los resultados de los análisis de hortalizas no demostraron la presencia de la bacteria, a diferencia de los altos porcentajes obtenidos en otros países de la región, de entre 20-30 por ciento, dependiendo de las condiciones de venta (principalmente empacado y refrigeración $\left.n^{1,3,6}\right)$. Esto, a pesar de que lo esperado es que se encuentren altamente contaminados, ya que Listeria es una bacteria cuyo hábitat normal es el suelo, por lo cual su presencia en hortalizas que crecen cerca del suelo como las analizadas (brócoli, coliflor, lechuga, repollo y espinaca) es bastante frecuente.

Otro factor a considerar es el punto de venta, las hortalizas ofrecidas en los supermercados, previo a su comercialización, pueden sufrir un proceso de desinfección, además provienen de cultivos que manejan buenas prácticas agrícolas como medio de asegurar la inocuidad de los mismos. Pero, esto no es de esperar en los productos analizados porque fueron colectados en los mercados de la ciudad, lo que significa que no son producidos ni expedidos de la manera adecuada.

Tal vez un punto a favor que explique la baja incidencia de Listeria tanto en hortalizas como en lácteos artesanales recolectados en los mercados es que no se mantienen en refrigeración para su venta y se conoce la capacidad de esta bacteria de crecer rápidamente a temperaturas bajas.

\section{CONCLUSIONES}

El objetivo primario de este estudio fue el de evaluar la calidad microbiológica de los productos alimenticios elegidos mediante el análisis de esta bacteria. De acuerdo con las normas nacionales e internacionales la presencia de cualquier microorganismo patógeno no es permitido en 25 gramos de muestra, tal es el caso

\footnotetext{
${ }^{1}$ Arias - Echandi ML y Antillon F. 2000. Contaminación microbiológica de los alimentos en Costa Rica, Una revisión de 10 años. Rev Biomed 11:113-122.

${ }^{3}$ De Curtis ML, Franceschi O, y De Castro N. 2002. Listeria monocytogenes en vegetales mínimamente procesados. Archivos latinoamericanos de nutrición Vol. 52 (3).

${ }^{6}$ Martínez R y Villalobos de Bastardo L. 2004. Aislamiento de Listeria monocytogenes en atún fresco expedido en la ciudad de Cumaná, Venezuela. Revista Científica Vol. 14 (4).
} 
de Listeria monocytogenes. A pesar de las limitaciones obvias de este estudio, como ser la cantidad de muestras analizadas y las zonas geográficas abarcadas, se puede decir entonces que el riesgo de contraer una infección y desarrollar una listeriosis es mínimo, aunque es difícil establecer una asociación entre los casos de listeriosis en nuestro país y la incidencia de la bacteria en diferentes tipos de alimentos. Sin embargo, una mejor evaluación de este riesgo sólo se puede lograr mediante el análisis sistemático de los alimentos que consume la población, responsabilidad que recae en los organismos nacionales pertenecientes al sector salud y veterinario, entre otros. Por otra parte, la enumeración de la bacteria por gramo de alimento en lugar de una prueba de presencia o ausencia en 25 gramos también nos permitiría una mejor evaluación del riesgo o al menos una evaluación de la exposición, es decir cambios en la frecuencia y el grado de contaminación del alimento, desde la venta hasta el consumo.

\section{AGRADECIMIENTO}

Agradecemos la participación de los estudiantes de la clase de investigación, Alicia Rivera, Tania Castillo, Isis Santos y Lenin Escobar, quienes formaron parte del grupo de trabajo de toma de y análisis de muestra. Asimismo, agradecemos a la Dirección de Investigación Científica de la UNAH por el financiamiento de esta investigación. 